\title{
A 5-Year Evaluation of the Implementation of Triple Diagnostics for Early Detection of Severe Necrotizing Soft Tissue Disease: A Single-Center Cohort Study
}

\author{
Femke Nawijn ${ }^{1}$ (D) $\cdot$ Roderick M. Houwert $^{1} \cdot$ Karlijn P. J. van Wessem $^{1} \cdot$ \\ Rogier K. J. Simmermacher ${ }^{1}$ Geertje A. M. Govaert ${ }^{1}$ - Marijke R. van Dijk ${ }^{2}$. \\ Mirjam B. de Jong ${ }^{1}$ Ivar G. J. de Bruin ${ }^{1}$ Luke P. H. Leenen ${ }^{1}$ - Falco Hietbrink ${ }^{1}$
}

Published online: 5 April 2019

(C) The Author(s) 2019

\begin{abstract}
Background The standardized approach with triple diagnostics (surgical exploration with visual inspection, microbiological and histological examination) has been proposed as the golden standard for early diagnosis of severe necrotizing soft tissue disease (SNSTD, or necrotizing fasciitis) in ambivalent cases. This study's primary aim was to evaluate the protocolized approach after implementation for diagnosing (early) SNSTD and relate this to clinical outcome.

Methods A cohort study analyzing a 5-year period was performed. All patients undergoing surgical exploration (with triple diagnostics) for suspected SNSTD since implementation were prospectively identified. Demographics, laboratory results and clinical outcomes were collected and analyzed.

Result Thirty-six patients underwent surgical exploration with eight (22\%) negative explorations. The overall 30-day mortality rate was $25 \%$, with an early, SNSTD-related mortality rate of $11 \%(n=3)$. Of these, one patient $(4 \%)$ underwent primary amputation, but died during surgery. No significant differences between baseline characteristics were found between patients diagnosed with SNSTD in early/indistinctive or late/obvious stage. Patient diagnosed at an early stage had a significantly shorter ICU stay ( 2 vs. 6 days, $p=0.031$ ). Mortality did not differ between groups; patients who died were all ASA IV patients.

Conclusion Diagnosing SNSTD using the approach with triple diagnostics resulted in a low mortality rate and only a single amputation in a pre-terminal patient in the first 5 years after implementation. All deceased patients had multiple preexisting comorbidities consisting of severe systemic diseases, such as end-stage heart failure. Early detection proved to facilitate faster recovery with shorter ICU stay.
\end{abstract}

Femke Nawijn

f.nawijn-2@umcutrecht.nl

Roderick M. Houwert

r.m.houwert@umcutrecht.nl

Karlijn P. J. van Wessem

kwessem@umcutrecht.nl

Rogier K. J. Simmermacher

r.k.j.simmermacher@umcutrecht.nl

Geertje A. M. Govaert

g.a.m.govaert@umcutrecht.nl

Marijke R. van Dijk

m.r.vandijk-20@umcutrecht.nl
Mirjam B. de Jong

m.b.dejong-33@umcutrecht.nl

Ivar G. J. de Bruin

i.g.j.debruin-5@umcutrecht.nl

Luke P. H. Leenen

1.p.h.leenen@umcutrecht.nl

Falco Hietbrink

f.hietbrink@umcutrecht.nl

Department of Surgery, University Medical Center Utrecht, Heidelberglaan 100, 3584 CX, Utrecht, The Netherlands

2 Department of Pathology, University Medical Center Utrecht, Heidelberglaan 100, Utrecht, The Netherlands 


$\begin{array}{ll}\text { Abbreviations } \\ \text { ASA } & \text { American Society of Anesthesiologists } \\ \text { GAS } & \text { Group A Streptococcus } \\ \text { ICU } & \text { Intensive care unit } \\ \text { IQR } & \text { Interquartile range } \\ \text { LRINEC } & \begin{array}{l}\text { Laboratory risk indicator for necrotizing } \\ \text { fasciitis }\end{array} \\ \text { NSTI } & \text { Necrotizing soft tissue infection } \\ \text { SD } & \text { Standard deviation } \\ \text { SNSTD } & \begin{array}{l}\text { Severe necrotizing soft tissue disease } \\ \text { STROBE }\end{array} \\ & \begin{array}{l}\text { Strengthening the reporting of observational } \\ \text { studies in epidemiology }\end{array}\end{array}$

\section{Introduction}

Severe necrotizing soft tissue disease (SNSTD, or necrotizing fasciitis) is a rapidly spreading and life-threatening infection with subsequent necrosis of the fascia often extending into the skin, soft tissue and muscles $[1,2]$. If untreated, the development of septic shock is inevitable and the infection will have a mortality rate reaching $100 \%$ [1, 3]. Early recognition, immediate aggressive surgical debridement, adequate antibiotic coverage and, if necessary in cases of sepsis, aggressive resuscitation should reduce mortality $[2,4,5]$. However, diagnosing SNSTD timely remains one of the greatest challenges in managing the disease $[6,7]$. There are no pathognomonic early signs of SNSTD available to differ between other less severe soft tissue infections such as cellulitis or erysipelas, resulting in a high rate of misdiagnoses $[2,7,8]$. Therefore, the consensus is that the diagnosis can only be established surgically [1-4].

Since a direct correlation between delayed diagnosis and mortality has been demonstrated, the diagnostic process should improve [3, 7, 9]. Therefore, triple diagnostics (surgical exploration with visual inspection, microbiological and histological examination) has been advocated as the golden standard for diagnosing SNSTD in ambivalent cases $[3,5,10]$. If fascial necrosis is macroscopically evident, the treating surgeon can immediately start debridement. If the exploration remains indecisive (i.e., fascial edema), further diagnostics with intra-operative fresh-frozen section and Gram stain of fascial biopsies should be obtained. Histological signs of fascial necrosis or bacterial invasion warrant further exploration and debridement. In case of negative finding, the procedure can be discontinued with assumed little risk or morbidity for the patient [5]. Five years ago, the approach of diagnosing SNSTD using triple diagnostics was protocolized at our hospital. Therefore, this study's primary aim is to evaluate the diagnostic and clinical outcomes achieved after implementation of triple diagnostics for suspected SNSTD.

\section{Materials and methods}

The institutional review board provided a waiver (WAG/ om/15/032329) for retrospective data collection.

\section{Study design}

A single-center cohort study was performed for all patients with suspected SNSTD undergoing surgical exploration at an academic level I trauma center and tertiary referral center, as part of the standardized approach with triple diagnostics. All patients over 18 years and undergoing triple diagnostics for suspected diagnosis of SNSTD since its implementation at this hospital in January 2013 were prospectively identified and included for quality evaluation. Patients not undergoing surgical exploration based on clinical symptoms evaluated by the surgeon were excluded.

\section{The approach of triple diagnostics}

The algorithm used for diagnosing SNSTD in our cohort, known as "triple diagnostics," is previously described in an article by Hietbrink et al. [5] and based on previous reports $[3,10]$. Patients presenting with clinical symptoms consisted with SNSTD were taken to the operation room if a fair suspicion for SNSTD remained after clinical evaluation of the presenting symptoms, vital parameters and laboratory values by the (attending) surgeon. The approach consists of surgical exploration with visual inspection of the infected soft tissues and when deemed necessary combined with histological and microbiological examination of a surgically obtained fascial sample in case of clinically suspected or indistinct SNSTD. The clinical diagnosis can be assured immediately based on intra-operative macroscopic findings of fascial necrosis or can remain indistinct. If the diagnosis remains ambivalent (i.e., perifascial edema), fascial biopsies should be examined intra-operatively as fresh-frozen section and Gram stain. Criteria for positive histological examination were necrosis of the superficial fascia, fibrinous thrombi of arteries and veins passing through fascia, angiitis with fibrinoid necrosis of vessel walls, infiltration of fascia (and deep dermis) with abundant polymorphonuclear neutrophils or microorganisms within the destroyed fascia and dermis $[5,11]$. Gram stain was conclusive for SNSTD if the fascial biopsy contained microbes with or without leukocytes [5]. To ensure reliable results from the fresh-frozen section and Gram stain, the surgeon should be aware that the biopsy taken for fresh-frozen section unequivocally consists of 
multiple tissue layers-from skin to muscle-of the affected area $[5,11,12]$. On the contrary, the biopsy sent for Gram stain should only consist of fascia and should be taken with sterile instruments with a no-touch technique to prevent contamination with colonizing skin flora [13]. Based on those results, the patient is allocated to one of the three treatment strategies (Table 1) [5]. For this study, all included patients were divided into one of these three groups as well based on the findings during surgical exploration.

Some of the patients in this cohort were previously published by Hietbrink et al. [5] as part of an evaluation of the triple diagnostics technique. For all identified patients, demographic characteristics (age, American Society of Anesthesiologists (ASA) classification, medical history), disease characteristics (location, cultures, hours since onset symptoms), vital functions, laboratory results (leukocytes, C-reactive protein, hemoglobin, sodium, creatinine, glucose, creatine kinase) and arterial blood gas results at presentation, hours from suspicion to surgery, intra-operative results of triple diagnostics, attempt at skin-sparing debridement, cultures results, length of hospitalization, length of intensive care unit (ICU) stay, amputation rate and in-hospital mortality were collected from the hospital's electronic medical chart. The laboratory results were used to calculate the laboratory risk indicator for necrotizing fasciitis (LRINEC) score at presentation for each patient [9]. Definitive culture results were used to classify the SNSTD in type I (polymicrobial), type II (monomicrobial) or type III (e.g., Clostridium spp. or Vibrio spp.) [1]. Early diagnosis of SNSTD was defined as the patients with only histological or microbiological signs of SNSTD (group 2), late diagnosis of SNSTD was defined as the patients with already macroscopic signs of fascial necrosis (group 1).

The primary outcomes of this study were the amputation and 30-day mortality rate. The secondary outcomes were length of hospital stay and ICU stay, which were compared between patients with macroscopic fascial necrosis and diagnosis established by triple diagnostics.

\section{Statistical analysis}

Continuous data were presented as means with standard deviation (SD) or medians with interquartile ranges (IQR). Categorical data were presented as frequencies with percentages. The independent sample's $t$ test was used to analyze normally distributed continuous variables and the two-tailed Mann-Whitney $U$ test for not normally distributed continuous variables and ordinal categorical variables. The Fisher exact test was used for nominal categorical variables. For all analyses, a two-sided $p<0.05$ was considered statistically significant. Data were analyzed using STATA (StataCorp. 2013. Stata Statistical Software: Release 13. College Station, TX: StataCorp LP).

\section{Results}

\section{Patient demographics}

After implementation, 36 patients underwent surgical exploration for suspicion of SNSTD. The average age of patients was $54 \pm 16$ years, and most patients had multiple comorbidities (66\% were ASA III or IV) (Table 2). Eight explorations with triple diagnostics (22\%) were negative for SNSTD, and 28 patients (78\%) were diagnosed with SNSTD. Of these, $16(57 \%)$ patients had macroscopic findings of necrotic fascia and/or muscle and $12(43 \%)$ patients were diagnosed based on macroscopic tissue edema combined with a positive fresh-frozen section or Gram stain (Fig. 1). There were no false positive or false negative debridements. The median time from suspicion to surgical exploration was $1 \mathrm{~h}$ and 15 min (Table 2). The longest time from suspicion to surgery being $9 \mathrm{~h}$ in one patient while all other patients were brought to the OR within $2.5 \mathrm{~h}$ after presentation. The treatment delay in this patient was caused by misjudgment of the severity of the symptoms during initial screening. The shortest time was 16 min between suspicion and surgery. Most SNSTDs were localized at the lower extremity $(n=21,58 \%)$, and Streptococcus pyogenes (also know as beta-hemolytic group A Streptrococcus (GAS)) was most often the isolated

Table 1 Possible treatment strategies based on standardized approach with triple diagnostics for diagnosing severe necrotizing soft tissue disease

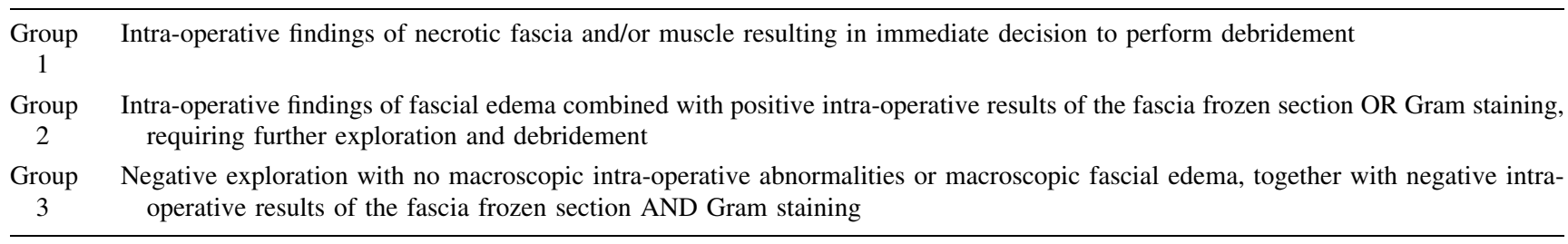


Table 2 Demographics of patients with clinical suspicion for severe necrotizing soft tissue disease divided by intra-operative findings

\begin{tabular}{|c|c|c|c|c|}
\hline & $\begin{array}{l}\text { Total } \\
n=36\end{array}$ & $\begin{array}{l}\text { Group } 1 \\
n=16 \\
(44 \%)\end{array}$ & $\begin{array}{l}\text { Group } 2 \\
n=12 \\
(33 \%)\end{array}$ & $\begin{array}{l}\text { Group } 3 \\
n=8(22 \%)\end{array}$ \\
\hline Age in years, mean $\pm S D$ & $54 \pm 16$ & $55 \pm 17$ & $52 \pm 16$ & $54 \pm 15$ \\
\hline \multicolumn{5}{|l|}{ ASA classification, $n(\%)$} \\
\hline I & $7(20)$ & $6(37)$ & $1(8)$ & $0(0)$ \\
\hline II & $5(14)$ & $3(19)$ & $1(8)$ & $1(12.5)$ \\
\hline III & $12(33)$ & $3(19)$ & $6(50)$ & $3(37.5)$ \\
\hline IV & $12(33)$ & $4(25)$ & $4(34)$ & $4(50)$ \\
\hline \multicolumn{5}{|l|}{ Medical history, $n(\%)$} \\
\hline Diabetes mellitus & $5(14)$ & $2(13)$ & $2(17)$ & $1(12.5)$ \\
\hline Cardiovascular disease & $15(42)$ & $7(44)$ & $5(42)$ & $3(37.5)$ \\
\hline Pulmonary disease & $11(31)$ & $4(25)$ & $5(42)$ & $2(25)$ \\
\hline Malignancy & $5(14)$ & $3(19)$ & $1(8)$ & $1(12.5)$ \\
\hline Auto-immune disease & $13(36)$ & $3(19)$ & $6(50)$ & $4(50)$ \\
\hline Morbid obesity (body mass index $\geq 35 \mathrm{~kg} / \mathrm{m}^{2}$ ) & $3(8)$ & $1(6)$ & $2(17)$ & $0(0)$ \\
\hline Surgery within past 30 days & $8(22)$ & $5(31)$ & $2(17)$ & $1(12.5)$ \\
\hline \multicolumn{5}{|l|}{ Locations with signs of SNSTD $n(\%)$} \\
\hline Head/neck & $3(8)$ & $2(12.5)$ & $1(8)$ & $0(0)$ \\
\hline Upper extremity & $3(8)$ & $2(12.5)$ & $1(8)$ & $0(0)$ \\
\hline Trunk & $6(17)$ & $4(25)$ & $1(8)$ & $1(12.5)$ \\
\hline Perineum & $2(6)$ & $2(12.5)$ & $0(0)$ & $0(0)$ \\
\hline Lower extremity & $21(58)$ & $6(37.5)$ & $8(66)$ & $7(87.5)$ \\
\hline Whole body ( $>50 \%$ of total body surface area affected) & $1(3)$ & $0(0)$ & $1(8)$ & $0(0)$ \\
\hline \multicolumn{5}{|l|}{ Vital functions at presentation, median (IQR) } \\
\hline Systolic blood pressure in $\mathrm{mmHg}^{\mathrm{a}}$ & $\begin{array}{l}117 \\
(90-139)\end{array}$ & $\begin{array}{l}110 \\
(80-120)\end{array}$ & $\begin{array}{l}118 \\
(87-148)\end{array}$ & $\begin{array}{l}131 \\
(115-140)\end{array}$ \\
\hline Pulse rate in beats per minute ${ }^{b}$ & $\begin{array}{l}104 \\
(87-114)\end{array}$ & $\begin{array}{l}109 \\
(84-114)\end{array}$ & $\begin{array}{l}107 \\
(84-119)\end{array}$ & $\begin{aligned} & 100 \\
&(91-112)\end{aligned}$ \\
\hline Breathing frequency per minute ${ }^{c}$ & $20(18-28)$ & $20(18-29)$ & $18(16-40)$ & 28 \\
\hline LRINEC Score $^{\mathrm{b}}$, mean $\pm \mathrm{SD}$ & $6 \pm 3$ & $7 \pm 2$ & $5 \pm 3$ & $5 \pm 3$ \\
\hline \multicolumn{5}{|l|}{ Laboratory results } \\
\hline Leukocytes in $10 \times 9 / \mathrm{L}$ (normal range: $4.0-10.010 \times 9 / \mathrm{L}$ ) median $(\mathrm{IQR})$ & $\begin{array}{l}11.7 \\
(6.8-18.3)\end{array}$ & $\begin{array}{r}13.2 \\
(5.5-21.6)\end{array}$ & $\begin{array}{l}11.6 \\
(8.7-13.2)\end{array}$ & $\begin{array}{l}10.5 \\
\quad(5.1-16.5)\end{array}$ \\
\hline $\mathrm{CRP}$ in $\mathrm{mg} / \mathrm{L}^{\mathrm{a}}$ (normal range: $<10 \mathrm{mg} / \mathrm{L}$ ), mean $\pm \mathrm{SD}$ & $231 \pm 144$ & $278 \pm 137$ & $216 \pm 157$ & $168 \pm 124$ \\
\hline $\begin{array}{l}\text { Hemoglobin in mmol/L (normal range: } \widehat{\jmath} 8.6-10.7 \mathrm{mmol} / \mathrm{L} ; \text {; } 7.4-9.6 \mathrm{mmol} / \mathrm{L} \text { ), } \\
\text { mean } \pm \mathrm{SD}\end{array}$ & $7.6 \pm 1.3$ & $7.8 \pm 1.2$ & $7.4 \pm 1.6$ & $7.5 \pm 1.4$ \\
\hline Sodium in mmol/L (normal range: $136-146 \mathrm{mmol} / \mathrm{L}$ ), median (IQR) & $\begin{array}{l}135 \\
(133-137)\end{array}$ & $\begin{array}{l}135 \\
(133-136)\end{array}$ & $\begin{array}{l}135 \\
(133-137)\end{array}$ & $\begin{array}{l}134 \\
(132-139)\end{array}$ \\
\hline $\begin{array}{l}\left.\text { Creatinine in } \mu \mathrm{mol} / \mathrm{L} \text { (normal range: } \sigma^{\uparrow} 64-104 \mu \mathrm{mol} / \mathrm{L} ; \text {; } 49-90 \mu \mathrm{mol} / \mathrm{L}\right)^{\mathrm{a}} \text {, } \\
\text { median }(\mathrm{IQR} \text { ) }\end{array}$ & $\begin{array}{l}112 \\
(78-196)\end{array}$ & $\begin{array}{l}167 \\
(107-338)\end{array}$ & $\begin{array}{l}119 \\
(58-216)\end{array}$ & $79(65-97)$ \\
\hline Glucose in $\mathrm{mmol} / \mathrm{L}$ (normal range: $3.5-7.8 \mathrm{mmol} / \mathrm{L}$ ), median (IQR) & $6.6(5.7-7.5)$ & $7.1(6.1-7.7)$ & $6.3(5.5-7.4)$ & $6.3(5.6-7.3)$ \\
\hline Creatine kinase in U/L $(\widehat{\jmath}<170 \mathrm{U} / \mathrm{L} ; ~+\uparrow<145 \mathrm{U} / \mathrm{L})^{\mathrm{d}}$, median $(\mathrm{IQR})$ & $\begin{array}{l}156 \\
(74-395)\end{array}$ & $\begin{array}{l}231 \\
(61-345)\end{array}$ & $\begin{array}{l}110 \\
(36-682)\end{array}$ & $\begin{array}{l}124(88- \\
180)\end{array}$ \\
\hline \multicolumn{5}{|l|}{ Arterial blood gas results at presentation, mean $\pm S D$} \\
\hline $\mathrm{pH}(\text { normal range: } 7.37-7.45)^{\mathrm{e}}$ & $7.38 \pm 0.11$ & $7.34 \pm 0.09$ & $7.39 \pm 0.10$ & $7.48 \pm 0.06$ \\
\hline $\mathrm{pCO}_{2}$ in $\mathrm{mmHg}$ (normal range: $\left.35-45 \mathrm{mmHg}\right)^{\mathrm{f}}$ & $35 \pm 9$ & $34 \pm 9$ & $37 \pm 10$ & $34 \pm 4$ \\
\hline Bicarbonate in mmol/L (normal range: $22-29 \mathrm{mmol} / \mathrm{L})^{\mathrm{e}}$ & $20 \pm 5$ & $18 \pm 4$ & $22 \pm 5$ & $25 \pm 2$ \\
\hline Base deficit in $\mathrm{mmol} / \mathrm{L}$ (normal range: -3 to $+3 \mathrm{mmol} / \mathrm{L}$ ) ${ }^{\mathrm{e}}$ & $5 \pm 6$ & $8 \pm 6$ & $3 \pm 6$ & $-1 \pm 2$ \\
\hline Hours since onset symptoms, median (IQR) & $24(20-66)$ & $24(12-72)$ & $24(20-48)$ & $42(24-69)$ \\
\hline Hours from suspicion to surgery, median (IQR) & $1.5(0.5-2)$ & $1(0.5-2)$ & $2(1.5-2.25)$ & $\begin{array}{l}1.75 \\
\quad(0.75-2.5)\end{array}$ \\
\hline
\end{tabular}


Table 2 continued

\begin{tabular}{|c|c|c|c|c|}
\hline & $\begin{array}{l}\text { Total } \\
n=36\end{array}$ & $\begin{array}{l}\text { Group } 1 \\
n=16 \\
(44 \%)\end{array}$ & $\begin{array}{l}\text { Group } 2 \\
n=12 \\
(33 \%)\end{array}$ & $\begin{array}{l}\text { Group } 3 \\
n=8(22 \%)\end{array}$ \\
\hline \multicolumn{5}{|l|}{ Intra-operative macroscopic findings, $n(\%)$} \\
\hline Necrotic fascia and/or muscle & $16(44)$ & $16(100)$ & $0(0)$ & $0(0)$ \\
\hline Edema of tissue and/or "dishwater" fluid & $16(44)$ & $0(0)$ & $12(100)$ & $4(50)$ \\
\hline No abnormalities & $4(11)$ & $0(0)$ & $0(0)$ & $4(50)$ \\
\hline \multicolumn{5}{|c|}{ Intra-operative fresh-frozen section results, $n(\%)$} \\
\hline Necrosis of fascia & $14(39)$ & $7(44)$ & $7(58)$ & $0(0)$ \\
\hline Suggestive findings for SNSTD & $8(22)$ & $2(12)$ & $5(42)$ & $1(12.5)$ \\
\hline Inflammation surrounding fascia & $2(6)$ & $0(0)$ & $0(0)$ & $2(25)$ \\
\hline No abnormalities & $8(22)$ & $4(25)$ & $0(0)$ & $4(50)$ \\
\hline Not performed & $4(11)$ & $3(19)$ & $0(0)$ & $1(12.5)$ \\
\hline \multicolumn{5}{|l|}{ Intra-operative Gram stain results, $n(\%)$} \\
\hline Bacteria in fascia & $28(78)$ & $15(94)$ & $12(100)$ & $1(12.5)$ \\
\hline No bacteria in fascia & $7(19)$ & $0(0)$ & $0(0)$ & $7(87.5)$ \\
\hline Not performed & $1(3)$ & $1(6)$ & $0(0)$ & $0(0)$ \\
\hline \multicolumn{5}{|l|}{ Type of $\mathrm{SNSTD}^{\mathrm{b}}, n(\%)$} \\
\hline Type I & $7(26)$ & $4(25)$ & $3(27)$ & NA \\
\hline Type II & $18(67)$ & $11(69)$ & $7(64)$ & NA \\
\hline Type III & $2(7)$ & $1(6)$ & $1(9)$ & NA \\
\hline \multicolumn{5}{|l|}{ Final cultures, $n(\%)$} \\
\hline Streptococcus pyogenes & $17(61)$ & $10(62.5)$ & $5(42)$ & NA \\
\hline Mixed flora & $5(18)$ & $3(19)$ & $2(17)$ & NA \\
\hline Vibrio species or Clostridium species & $1(4)$ & $1(6)$ & $0(0)$ & NA \\
\hline Isolated other bacteria & $4(14)$ & $2(12.5)$ & $4(33)$ & NA \\
\hline No further differentiation & $1(4)$ & $0(0)$ & $1(8)$ & NA \\
\hline \multicolumn{5}{|l|}{ Type of debridement, $n(\%)$} \\
\hline Skin-sparing debridement & $1(4)$ & $0(0)$ & $1(8)$ & NA \\
\hline Partial skin-sparing debridement & $8(28)$ & $5(31)$ & $3(25)$ & NA \\
\hline No attempt at skin-sparing debridement & $18(64)$ & $11(69)$ & $7(59)$ & NA \\
\hline No resection due to "to much" & $1(4)$ & $0(0)$ & $1(8)$ & NA \\
\hline
\end{tabular}

ASA American Society of Anesthesiologists, CRP C-reactive protein, IQR Interquartile range, LRINEC laboratory risk indicator for necrotizing fasciitis, $N A$ not applicable, $S D$ standard deviation, $S N S T D$ severe necrotizing soft tissue disease

Missing cases: ${ }^{\mathrm{a}} 1$ missing, ${ }^{\mathrm{b}} 2$ missing, ${ }^{\mathrm{c}} 18$ missing, ${ }^{\mathrm{d}} 16$ missing, ${ }^{\mathrm{e}} 4$ missing, ${ }^{\mathrm{f}} 5$ missing

causative microorganism $(n=17,61 \%)$. The mean LRINEC score at admission was $6 \pm 3$, which differed between groups (Group 1: $7 \pm 2$; Group 2: $5 \pm 3$; Group 3: $5 \pm 3)$.

\section{Clinical outcomes of positive exploration}

The overall 30-day mortality rate of SNSTD was 25\% $(n=7)$, with an early, direct SNSTD related, mortality rate of $11 \%(n=3)$. The 3 patients who died as a direct consequence of SNSTD all died within 2 days after admission.
The 4 additional patients with late mortality died as result of withdrawal of care due to severe comorbidities and poor preclinical condition. All seven patients who died were classified as ASA IV patients. Only one patient (4\%) underwent an amputation, which was performed within 30 min after presentation at the emergency room; however, he died during this surgery (his comorbidities included end-stage diastolic and systolic heart failure, cardiac output of $<15 \%$ ). Median length of hospitalization was 18 days (IQR 9-29), and median ICU stay was 3 days (IQR 1-8) (Table 3). 


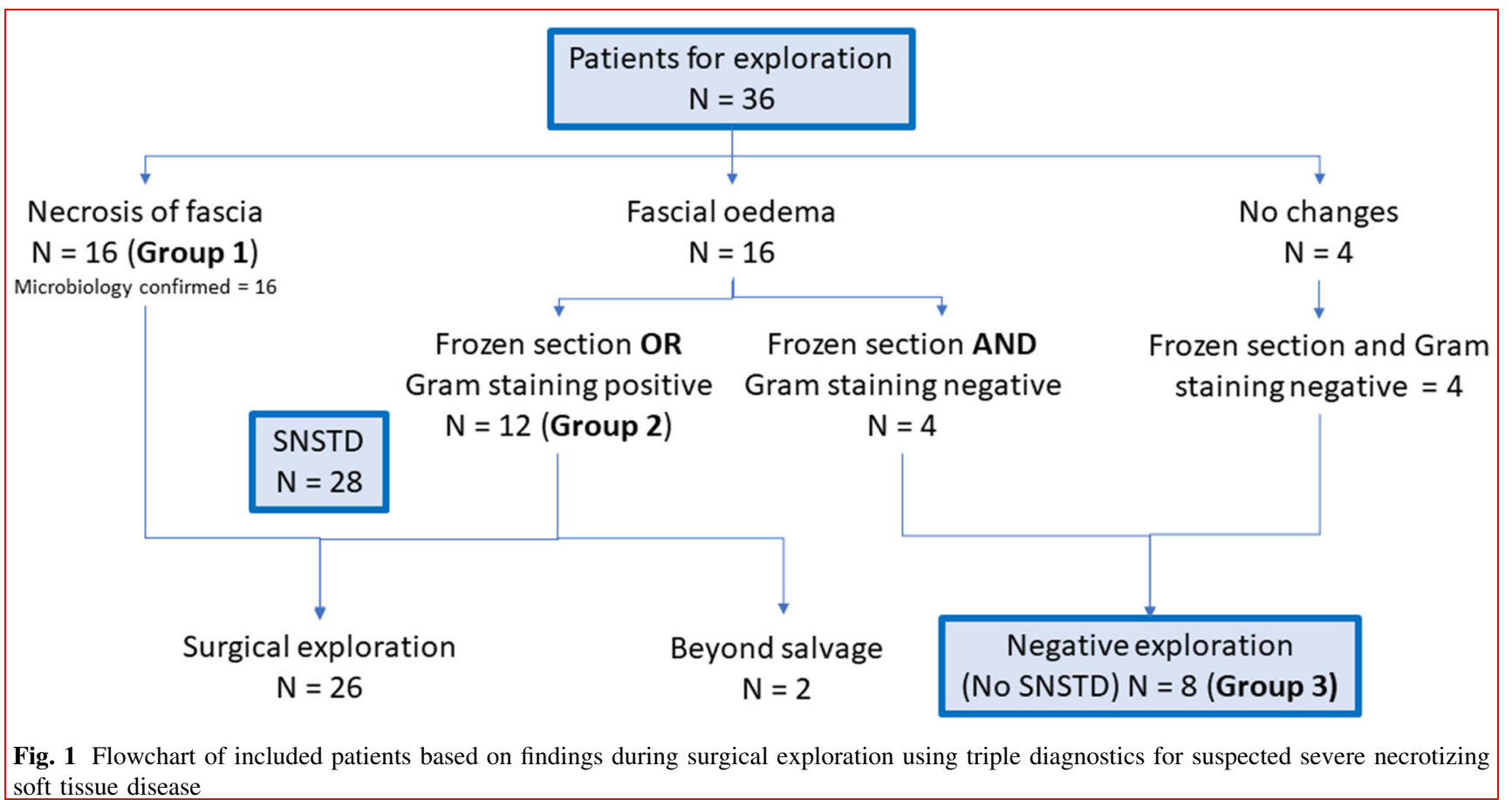

Table 3 Clinical outcomes of patients with confirmed diagnosis of severe necrotizing soft tissue disease

\begin{tabular}{|c|c|c|c|c|}
\hline & $\begin{array}{l}\text { Total SNSTD } \\
\text { patients } n=28(100 \%)\end{array}$ & $\begin{array}{l}\text { Group } 1 n=16 \\
(57 \%)\end{array}$ & $\begin{array}{l}\text { Group } 2 n=12 \\
(43 \%)\end{array}$ & $p$ value \\
\hline Length of hospital stay in days, median (IQR) & $18(9-29)$ & $23(12-34)$ & $167(5-19)$ & 0.285 \\
\hline Length of intensive care stay in days, median (IQR) & $3(1-8)$ & $6(3-10)$ & $2(0-3)$ & $\mathbf{0 . 0 3 1}$ \\
\hline Amputation, $n(\%)$ & $1(4)$ & $1(6)$ & $0(0)$ & 1.000 \\
\hline In-hospital mortality rate, $n(\%)$ & $7(25)$ & $4(25)$ & $3(25)$ & 1.000 \\
\hline ASA classification of deceased patients, median (IQR) & $4(4-4)$ & $4(4-4)$ & $4(4-4)$ & NA \\
\hline Death SNSTD related (e.g., MOF) & $3(11)$ & $2(12.5)$ & $1(8)$ & 1.000 \\
\hline Withdrawal of treatment due to comorbidities & $4(14)$ & $2(12.5)$ & $2(17)$ & 1.000 \\
\hline Days until death, median (IQR) & $2(1-7)$ & $5(1-19)$ & $2(1-3)$ & 0.593 \\
\hline Days until SNSTD-related death & $1(0-1)$ & $1(0-1)$ & 1 & 1.000 \\
\hline Days until death due to withdrawal of treatment due to comorbidities & $5(3-19)$ & $19(7-30)$ & $3(2-3)$ & 0.121 \\
\hline
\end{tabular}

ASA American Society of Anesthesiologists, IQR interquartile range, NA not applicable, SNSTD severe necrotizing soft tissue disease

\section{Factors associated with negative exploration}

Most of the arterial blood gas results $(\mathrm{pH}$, bicarbonate and base deficit) at admission deviated from their normal values in patients with SNSTD compared to patients with negative exploration. Furthermore, patients with a positive exploration for SNSTD had an elevated median creatinine (137 $\mu \mathrm{mol} / \mathrm{L}$ (IQR 96-267) vs. $79 \mu \mathrm{mol} / \mathrm{L}$ (IQR 65-97), $p=0.033$ ). LRINEC score did not significantly differ between patients with positive and negative exploration ( $6 \pm 3$ vs. $5 \pm 3, p=0.253$ ), as all patients were critically ill (Table 2). A base deficit greater than $3 \mathrm{mmol} / \mathrm{L}$ appeared to have the highest predictive value for presence of SNSTD $(p=0.001), \mathrm{pH}(p=0.032)$ and bicarbonate
( $p=0.002)$ below reference values were as well associated with a positive diagnose.

\section{Effect of early SNSTD recognition}

No statistically significant difference between patient and disease characteristics was found between patients in group 1 and group 2. There appeared to be a small difference in LRINEC score ( $7 \pm 2$ for group 1 vs. $5 \pm 3$ for group 2), however, not statistically significant. Both groups had similar vital functions, laboratory tests and arterial blood gas results (Table 2). A significant difference in outcome was found between patients diagnosed in an earlier stage of SNSTD (group 2) and patients with already more 
progressive SNSTD (group 1), being a significantly shorter ICU stay ( 2 vs. 6 days, $p=0.031$ ) for patients in group 2 (Table 3). No difference in direct SNSTD-related mortality was found between both groups $(n=2,12.5 \%$ in group 1 vs. $n=1,8 \%$ in group 2 ) (Fig. 1 and Table 3 ).

\section{Discussion}

Diagnosing SNSTD using the approach with triple diagnostics resulted in a low mortality rate and only a single amputation in a pre-terminal patient in the first 5 years after implementation. All deceased patients had multiple preexisting comorbidities consisting of severe systemic diseases, such as end-stage heart failure. Early detection also proved to facilitate faster recovery with shorter ICU stay. An arterial base deficit greater than $3 \mathrm{mmol} / \mathrm{L}$ was associated with a positive SNSTD diagnosis, whereas LRINEC scores could not differentiate between a positive and a negative diagnosis in this cohort.

Over the past years, the literature described an average mortality rate of $34 \%$ with a range from $6 \%$ up to as high as $76 \%[1,4,9,14]$. This study reports on the results of an overall 30-day mortality of $25 \%$, with an early, direct SNSTD-related mortality rate of $11 \%$. Furthermore, the length of ICU stay was shorter compared to the 11 days or longer described in the previous literature [3, 4, 15]. Patients who were diagnosed in an earlier stage had even a shorter ICU stay than patient with more progressive disease indicating less need for supportive care, while no differences in baseline laboratory or vital parameters could be identified. This further stresses the need for a timely diagnosis. Accurate diagnosis in the early stage of the disease prevents extensive involvement of limbs and other body regions, thereby reducing the risk of extensive debridement [12]. This current study shows that, with early diagnosis, no amputation was necessary in surviving patients, compared with previously described rates between 10 and 22\% [15, 16].

Triple diagnostics requires proper allocation of the patients with ambivalent SNSTD to hospitals with 24/7 available microbiologists and pathologists; however, this is affected by the logistic possibilities of the institution or regional collaboration. In case of evident signs of SNSTD during clinical evaluation, triple diagnostics is less likely to be needed intra-operative and therefore, the patient should undergo immediate surgical debridement regardless of the availability of a microbiologist or pathologist at that hospital. If needed, the patient could be transferred after the debridement, or if the appropriate logistics are in place, even prior to exploration without causing treatment delay. In case of ambivalent signs of SNSTD, the patient needs to be at a hospital that is equipped with the resources necessary to perform surgical exploration with triple diagnostics to prevent unnecessary debridement due to too much caution, or refrainment and/or delay of debridement due to unjust reassurance based on macroscopic findings.

Partly due to logistic reasons, the use of fresh-frozen section for diagnosing SNSTD is still debated and in most hospitals not (fully) implemented, even though it has been associated with reduced mortality rates [10-12]. Solomon et al. previously argued that it is not reliable as an independent test, and Anaya et al. stated that the use of freshfrozen section is not practical and too time-consuming $[6,17]$. However, this is if all cases are considered, including those with evidential macroscopic necrosis. We agree that in these cases, analysis should not lead to paralysis and prompt debridement is indicated. However, in ambivalent cases with perifascial edema, pathologists can often establish a diagnosis within $30 \mathrm{~min}$ after receiving the specimen, providing rapid and accurate results intra-operatively [10-12]. This requires an entire surgical team to wait for the results, and thus, logistics should be optimized. Nevertheless, when this half an hour adequately decreases the number of false negative explorations, this is worth the time and resource investments. This current study supports that theory, since 12 patients with suspicion for SNSTD had no macroscopic necrotic fascia or muscle, but their fascial biopsies showed on histological and microbiological examination signs consisting with SNSTD. As well as that four patients had fascial edema but did not have SNSTD based on histological and microbiological examination, preventing unnecessary debridement. Therefore, microscopic findings overrule macroscopic findings, since macroscopic findings are only visible if the infection has progressed far enough but might be preceded by histopathological change. Simultaneously, fascial biopsies should be sent for Gram staining. Results of Gram staining are known within approximately $30 \mathrm{~min}$ and can confirm diagnosis and guide the antibiotic regimen. This method is not able to completely rule out SNSTD, since culture results are needed to provide a definitive answer for ruling out SNSTD [5]. The sensitivity of diagnosing ambivalent SNSTD using the tests independentlymacroscopic findings, fresh-frozen sections or Gram stain - is not optimal, but combined led to no false negative explorations [5, 17]. The current study shows that all patients with no abnormal macroscopic findings-no necrotic fascia/muscle and fascial edema-had negative diagnoses; this indicates that triple diagnostics in those cases might not be necessary to rule out SNSTD.

It should be kept in mind that the patients presented in this study, and undergoing surgical exploration, are just a small selection of all patients presenting to our hospital with suspicion for SNSTD. This described strategy resulted in $22 \%$ negative explorations. Nevertheless, lowering this 
number should be weighed against the improved survival and amputation rates.

Survival remains the primary goal in treating SNSTD; however, further reduction in mortality-even when triple diagnostics is used-appears to be challenging. After optimization of the diagnostic process, further reduction in mortality seems to be mainly limited by patients' demographics, since all patients who died had (multiple) severe preexisting comorbidities. Therefore, when this mortality rate proves to be persistent, future SNSTD research should aim their recourses to decreasing morbidity, such as reduced ICU length of stay. However, studies assessing (long-term) morbidity after surviving SNSTD are limited [18, 19].

The results of this study provide practice-based evidence but should be interpreted in the right context. Selection bias was limited due to the prospective identification of patients; however, information bias remained in some degree due to the partial retrospective data collection. The retrospective data collection resulted in some missing vital parameters and laboratory test results at presentation; furthermore, the time from onset of symptoms to presentation was therefore estimated.

Concluding, the use of a standardized approach for diagnosing SNSTD using triple diagnostics for ambivalent cases has resulted in a reduced mortality and no amputations in the surviving patients. Early detection also proved to facilitate faster recovery with shorter ICU stay. Survival remains the primary goal; however, further reduction in mortality might be limited by the severity of comorbidities prior to onset of disease.

\section{Compliance with ethical standards}

Conflict of interest All authors declare that they have no conflict of interest.

Ethical approval The institutional review board of University Medical Center Utrecht provided a waiver for retrospective data collection.

Open Access This article is distributed under the terms of the Creative Commons Attribution 4.0 International License (http://crea tivecommons.org/licenses/by/4.0/), which permits unrestricted use, distribution, and reproduction in any medium, provided you give appropriate credit to the original author(s) and the source, provide a link to the Creative Commons license, and indicate if changes were made.

\section{References}

1. Misiakos EP, Bagias G, Patapis P, Sotiropoulos D, Kanavidis P, Machairas A (2014) Current concepts in the management of necrotizing fasciitis. Front Surg 1:36
2. Hakkarainen TW, Kopari NM, Pham TN, Evans HL (2014) Necrotizing soft tissue infections: review and current concepts in treatment, systems of care, and outcomes. Curr Probl Surg 51(8):344

3. Misiakos EP, Bagias G, Papadopoulos I, Danias N, Patapis P, Machairas N et al (2017) Early diagnosis and surgical treatment for necrotizing fasciitis: a multicenter study. Front Surg 4:5

4. Lancerotto L, Tocco I, Salmaso R, Vindigni V (2012) Necrotizing fasciitis: classification, diagnosis, and management. J Trauma 72(3):560

5. Hietbrink F, Bode LG, Riddez L, Leenen LPH, van Dijk MR (2016) Triple diagnostics for early detection of ambivalent necrotizing fasciitis. World J Emerg Surg 11(1):51

6. Anaya D, Dellinger E (2007) Necrotizing soft-tissue infection: diagnosis and management. Clin Infect Dis 44(5):705

7. Goh T, Goh L, Ang C, Wong C (2014) Early diagnosis of necrotizing fasciitis. Br J Surg 101:e119-e125

8. Fernando S, Tran A, Cheng W, Rochwerg B, Kyeremanteng K, Seely AJ, et al. (2019) Necrotizing soft tissue infections: diagnostic accuracy of physical examination, imaging, and LRINEC score: A systematic review and meta-analysis. Ann Surg 269(1):58-65

9. Wong CH, Khin LW, Heng KS, Tan KC, Low CO (2004) The LRINEC (Laboratory Risk Indicator for Necrotizing Fasciitis) score: a tool for distinguishing necrotizing fasciitis from other soft tissue infections. Crit Care Med 32(7):1535

10. Stamenkovic I, Lew P (1984) Early recognition of potentially fatal necrotizing fasciitis. N Engl J Med 310(26):1689

11. Stegeman SA, Nijhuis I, Van Leeuwen AM, Bonsing BA, Steenvoorde P (2012) The value of frozen section biopsy in diagnosing necrotizing fasciitis: proposal of a new grading system. J Tissue Viability 21(1):13

12. Majeski J, Majeski E (1997) Necrotizing Fasciitis: improved survival with early recognition by tissue biopsy and aggressive surgical treatment. South Med J 90(11):1065

13. Boyanova L (2018) Direct Gram staining and its various benefits in the diagnosis of bacterial infections. Postgrad Med 130(1):105

14. Nawijn F, Wassenaar ECE, Smeeing DPJ, Vlaminckx BJM, Reinders JSK, Wille J et al (2019) Exhaustion of the immune system by Group A Streptococcus necrotizing fasciitis: the occurrence of late secondary infections in a retrospective study. Trauma Surg Acute Care Open 4:e00027

15. Van Stigt SFL, De Vries J, Bijker JB, Mollen RMHG, Hekma EJ, Lemson SM et al (2016) Review of 58 patients with necrotizing fasciitis in the Netherlands. World J Emerg Surg 11(1):21

16. Dworkin MS, Westercamp MD, Park L, McIntyre A (2009) The epidemiology of necrotizing fasciitis including factors associated with death and amputation. Epidemiol Infect 137(11):1609

17. Solomon IH, Borscheid R, Laga AC, Askari R, Granter SR (2018) Frozen sections are unreliable for the diagnosis of necrotizing soft tissue infections. Mod Pathol 31(4):546

18. Hakkarainen TW, Ikebata NB, Bulger E, Evans HL (2014) Moving beyond survival as a measure of success: understanding the patient experience of necrotizing soft-tissue infections. J Surg Res 192(1):143

19. Pham TN, Moore ML, Costa BA, Cuschieri J, Klein MB (2009) Assessment of functional limitation after necrotizing soft tissue infection. J Burn Care Res. 30(2):301

Publisher's Note Springer Nature remains neutral with regard to jurisdictional claims in published maps and institutional affiliations. 